\title{
ANÁLISE DO PERCURSO POLÍTICO-PEDAGÓGICO DE UM ESTÁGIO: REFLEXÕES DE EXPERIMENTAÇÕES VIVENCIADAS EM UMA ESCOLA
}

\author{
Luiz Eduardo de Almeida ${ }^{1}$ \\ Davy de Melo Mendes ${ }^{2}$ \\ Gabriela Fernandes de Paiva Oliveira ${ }^{2}$ \\ Isadora de Barros Almeida ${ }^{2}$ \\ Júlia Neves Pereira da Silva ${ }^{2}$
}

\begin{abstract}
Resumo: Objetivo: analisar as significâncias político-pedagógicas de experimentações de um estágio odontológico. Metodologia: estudo qualitativo, narrativo-descritivo e argumentativo. Resultados: o "Estágio de Clínica Integrada em Atenção Primária" foi didaticamente sistematizado em dois periodos, "Pré-intervenção" e "Intervenção". Do primeiro, se desvendaram duas ações, a "Contextualização dos acadêmicos estagiários" e a "Estruturação, Ambientalização e Levantamento de necessidades do ambiente de trabalho". Já o segundo foi guiado pelo instrumento "TPC" (Teorizar-Praticar-Criticar), onde todas as ações seguiram a lógica do planejamento estratégico, ou seja, contextualizadas ao cenário de prática (ambiente escolar). Conclusão: das vivências algumas inferências se destacaram: a efetividade do instrumento "TPC" no planejamento estratégico de ações de educação em saúde; o reconhecimento do ambiente escolar como território fértil para ações promotoras de saúde; a importância de se disseminar, em espaços científicos, os aprendizados advindos de experimentações práticas de estágios.
\end{abstract}

Descritores: Promoção da saúde. Educação em saúde. Estágio clínico. Relações ComunidadeInstituição. Planejamento estratégico.

\section{ANALYSIS OF THE POLITICAL-PEDAGOGICAL COURSE OF AN ACADEMIC INTERNSHIP: REFLECTIONS OF EXPERIENCES IN A SCHOOL}

\begin{abstract}
Objective: to analyze the political-pedagogical significance of experiments of a dental stage. Methodology: qualitative, narrative-descriptive and argumentative study. Results: the "Internship of Integrated Clinic in Primary Care" was didactically systematized in two periods, "Pre-intervention" and "Intervention". From the first one, two actions were unveiled: the "Contextualization of the Interns" and the "Structuring, Environmentalization and Survey of Work Environment Needs". The second guided by the instrument "TPC", (Theorize-Practice-Criticize), where all actions followed the logic of strategic planning, contextualized to the practice scenario (school environment). Conclusion: from the experiences some inferences stood out: the effectiveness of the "CPT" instrument in the strategic planning of health education actions; the recognition of the school environment as a fertile territory for health promoting actions; the importance of disseminating, in scientific spaces, the learning that comes from practical experimentation of internships.
\end{abstract}

Descriptors: Health promotion. Health education. Clinical clerkship. Community-institutional relations. Strategic planning.

\section{ANÁLISIS POLÍTICO-PEDAGÓGICO DE UNA PASANTÍA: REFLEXIONES DE EXPERIENCIAS EN EL ENTORNO ESCOLAR}

Resumen: Objetivo: analizar el significado político-pedagógico de los experimentos de una etapa dental. Metodología: estudio cualitativo, narrativo descriptivo y argumentativo. Resultados: la "Práctica de Clínica Integrada en Atención Primaria" se sistematizó didácticamente en dos períodos, "Pre-intervención" e "Intervención". Desde la primera, se dieron a conocer dos acciones: la "Contextualización de los pasantes" y la "Estructuración, ambientalización y estudio de las necesidades del entorno laboral". El segundo fue guiado por el instrumento "TPC" (Teorizar-Practicar-Criticar), donde todas las acciones siguieron la lógica de la planificación estratégica, es decir, contextualizadas al escenario de práctica (ambiente escolar). Conclusión: de las experiencias se destacaron algunas inferencias: la efectividad del instrumento "CPT" en la planificación estratégica de las acciones de educación sanitaria; el reconocimiento del ambiente escolar como un territorio fértil para acciones de

\footnotetext{
${ }^{1}$ Docente do Departamento de Odontologia Restauradora da Faculdade de Odontologia da Universidade Federal de Juiz de Fora.

${ }^{2}$ Discente do curso de Odontologia da Universidade Federal de Juiz de Fora.
} 
promoción de la salud; La importancia de difundir, en espacios científicos, el aprendizaje que surge de la experimentación práctica de las prácticas.

Descriptores: Promoción de la salud. Educación en salud. Prácticas clínicas. Relaciones comunidade-institución. Planificación estratégica.

\section{Introdução}

Em linhas gerais, pode-se afirmar que a consolidação do processo educacional se esbarra na dialética relação entre o pensar e o fazer. Afinal, teoria sem prática se tornaria puro idealismo e abstração, e o contrário se revelaria mero espontaneísmo, pragmatismo (TINTI, 2015).

Refletindo sobre o exposto, pode-se afirmar que práticas educativas que não se esmeram na redução do distanciamento entre o pensar e o fazer se tornam antidialógicas, ou seja, descontextualizadas das condições sociais que a determinam, ou melhor, a justificam.

Sob a mesma lógica, no que tange a reorientação da formação dos profissionais de saúde, a referida interface pensar/fazer se evidencia (ALBUQUERQUE et al., 2008; MADEIRA, 2006). É deste enlaçamento que se dinamiza um indissociável círculo virtuoso, afinal, são nos cenários práticos (naturalmente extensionistas) que se dão a socialização do resultado de um fato (pesquisa) e/ou de um aprendizado (ensino) (ALMEIDA, PEREIRA, OLIVEIRA, 2016; ALMEIDA, 2009).

Imbricado ao contexto, os estágios supervisionados emergem como abordagens extramuros fundamentais para o processo formativo dos futuros profissionais de saúde ${ }^{6}$, pois, segundo Bruder et al (2017), p.297, “Os estágios supervisionados são considerados espaços no curso de graduação que permitem integrar o aluno ao contexto social e econômico da região de atuação, nos quais são realizados trabalhos que vão desde a educação em saúde até a reversão dos danos causados pelas doenças”.

Contudo, apesar de seus consolidados benefícios, as atividades desenvolvidas nos estágios, pela frequente atribuição genérica que lhe é estabelecida, ainda se conflitam com corriqueiras questões, normalmente atreladas à discussões sobre "onde", "como", e "quando" devem ser realizados (MOIMAZ et al., 2016).

A partir de então, imbrica-se uma inquietação, a necessidade de se discutir e, principalmente, de se prover um modelo de ensino pautado nas simbióticas relações entre educação (“o pensar”) e trabalho (“o fazer”), ou seja, um processo construído na e para realidade, que, segundo Almeida (2009), uma premissa que se encerra no reconhecimento da prática como fundamento, critério e finalidade da teoria.

Por fim, atravessado pelo exposto, o presente estudo não apenas se justifica, como alicerçou o seu propósito, analisar os possíveis impactos trazidos pelo "Estágio de Clínica 
Integrada em Atenção Primária/ECIAP” junto à qualidade da formação acadêmica do curso de Odontologia da Universidade Federal de Juiz de Fora (UFJF). Para tal, traz um recorte analítico das experimentações político-pedagógicas atreladas ao desenvolvimento de ações educativopreventivas vivenciadas em um ambiente escolar.

\section{Percurso Metodológico}

Primeiramente, por envolver seres humanos, foi aprovado e liberado pelo Comitê de Ética em Pesquisa da Universidade Federal de Juiz de Fora, segundo Resolução 510/2016 do Conselho Nacional de Saúde (BRASIL, 2016).

Trata-se de um estudo qualitativo, estruturado sob estratégia narrativo-descritiva e moldado à técnica argumentativa. Por sua transversalidade, serão aqui referendados os acontecimentos vivenciados no primeiro semestre de 2019, mais precisamente entre os meses de março a julho.

Como já exposto, guiado pelos possíveis impactos trazidos pelo ECIAP junto à qualidade da formação acadêmica, o objeto do estudo se delineou na compreensão dos dispositivos político-pedagógicos atrelados às experimentações vivenciadas em um "Ambiente escolar" (Escola Municipal Santana Itatiaia, Juiz de Fora/MG).

Indo além, no tocante aos investigadores, tutores (docentes e odontólogos) e estagiários (acadêmicos do curso de Odontologia-UFJF), merece destacar a fusão de seus papéis, ora observadores, ora observados. É nesta duplicidade de funções que se consagra a observação participativa, pois nela, segundo Creswell (2007), p.188, “[...] os investigadores identificam explicitamente seus vieses, valores e interesses pessoais [...]”. Corroborando, Bell (2008), p.161, reconhece que

a observação participativa não é um método fácil de realizar, ou de analisar, mas apesar dos argumentos de seus críticos, é um estudo sistemático e disciplinado que, se bem realizado, ajuda muito no entendimento das ações humanas e traz consigo novas maneiras de encarar o mundo social ${ }^{11}$.

Deste percurso foi direcionada a coleta de dados. Essencialmente narrativo-descritiva, foi instrumentalizada pela utilização dos "Relatórios das atividades diárias do ECIAP". Contíguo, seguiu o processo analítico dos fatos. Neste momento, adentraram-se os elementos argumentativos do estudo, embebidos tanto pelas interpretações de seus sujeitos-autores, quanto pelo confronto junto à literatura científica. $\mathrm{O}$ que reforçou-se ainda mais o papel ativo dos pesquisadores, aqui, descobridores do significado das ações e das relações por eles vividas e percebidas.

De acordo com Minayo et al (1994), p. 24, 
Os autores que seguem tal corrente não se preocupam em quantificar, mas, sim, em compreender e explicar a dinâmica das relações sociais que, por sua vez, são depositárias de crenças, valores, atitudes e hábitos. Trabalham com a vivência, com a cotidianeidade e também com a compreensão das estruturas e instituições como resultados da ação humana objetivada. Ou seja, desse ponto de vista, a linguagem, as práticas e as coisas são inseparáveis.

Enfim, calcada no empoderamento de seus elementos empíricos, esta investigação não se baseou em testar hipótese, pelo contrário, galgou-se aqui uma oportunidade de ofertar a outros leitores um momento de autoanálise, afinal, muitos podem se identificar com determinados aspectos, situações e reflexões.

\section{Resultados em discussão}

O “Estágio de Clínica Integrada em Atenção Primária/ECIAP” integra, desde 2008, a grade curricular do curso de Odontologia da Universidade Federal de Juiz de Fora (UFJF). Em conformidade com o ementário do Projeto Político Pedagógico, o "ECIAP” visa

Propiciar ao aluno estagiário oportunidades de executar, em cenário de prática, ações de promoção e prevenção em saúde, evidenciando o território bucal. Neste processo, o acadêmico poderá experimentar o papel do cirurgião-dentista no planejamento, no desenvolvimento e, principalmente, na análise crítica e reflexiva de todas as ações programadas.

Destinado a acadêmicos do $2^{\circ}$ período, o "ECIAP" conta com 120 horas de carga horária total, sendo 08 semanais. Contempla a matrícula de até 50 acadêmicos estagiários, equitativamente distribuídos em 02 turmas, A (segunda-feira das 14 às 18 h e quarta-feira das 8 às 12h) e B (quarta-feira das 8 às $12 \mathrm{~h}$ e sexta-feira das 14 às $18 \mathrm{~h}$ ).

Indo além, na intenção de prover uma melhor relação tutor-estagiário, cada turma foi dividida em cinco frentes de trabalho (Grupos I-A/B, II I-A/B, III I-A/B, IV I-A/B e V I-A/B). Neste estudo, que integra o processo avaliativo da disciplina, descrevem-se, de forma crítica e reflexiva, as investigações do Grupo II da Turma A, composta por 04 estagiários.

No que tange ao desenvolvimento de suas ações, de forma a otimizá-las, a lógica do trabalho pedagógico do "ECIAP" foi, e ainda o é didaticamente sistematizada em dois períodos, "Pré-intervenção" e “Intervenção", Imagem 1. 
Imagem 1: Dinamização do ECIAP, Autores (2019)

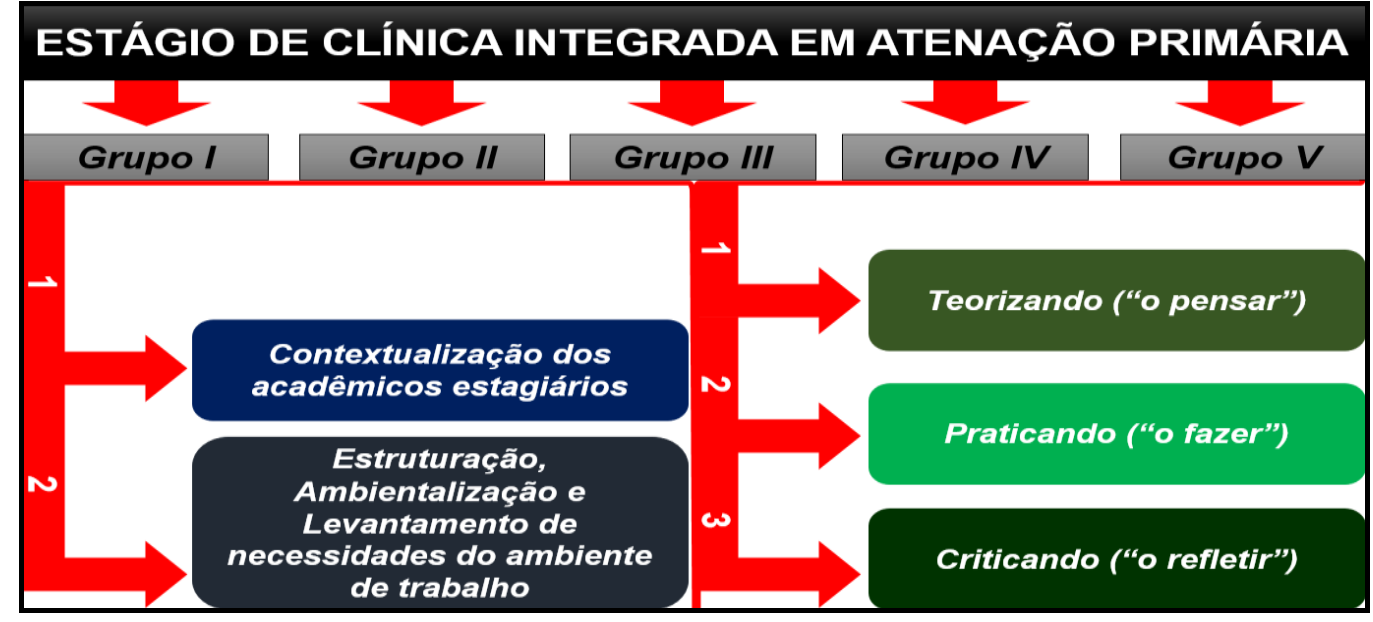

Do primeiro momento se desvendaram duas ações, a "Contextualização dos acadêmicos estagiários" e a "Estruturação, Ambientalização e Levantamento de necessidades do ambiente de trabalho".

Assim, como ponto de partida, coube aos tutores do "ECIAP" promoverem a imersão científica dos discentes estagiários frente aos seus futuros desafios práticos. Ressaltando neste estudo a evidenciação do desenvolvimento de atividades de educação em saúde em um ambiente escolar (Pré-escolares da Escola Municipal Santana Itatiaia, Juiz de Fora/MG).

Deste ciclo teorizante se desprenderam dois encontros (18/03 e 25/03/2019), sendo neles abordados os seguintes pontos de discussão: 1. Educação em saúde; 2. Educação em saúde em interface com a Odontologia; 3. Educação em saúde no ambiente escolar; 4. Planejamento estratégico para o desenvolvimento de ações de educação em saúde.

Neste ínterim, merecem destaque as técnicas de mediação, que, subsidiadas pelos ideários de diversos estudos, se deram por diferentes estratégias problematizadoras de ensino, destacando aulas expositivas, leitura crítica de artigos científicos, grupos de discussão e oficina para construção de materiais didáticos para educação em saúde (SALIBA et al., 2008; ROCHA et al., 2016; REUL et al., 2016; LAGE et al., 2017).

Seguindo, o período "Pré-intervenção" se encerrou com a "Estruturação, Ambientalização e Levantamento de necessidades do ambiente de trabalho".

Referente à "Estruturação", a Escola Municipal Santana Itatiaia conta com 10 salas, sendo 05 por turno, matutino e vespertino. Assim, buscando cobertura total deste ambiente, cada grupo de trabalho do estágio ficou responsável por uma turma de pré-escolares, ou seja, ao Grupo II da Turma A foi direcionada a sala 02 diurna/vespertina (22 crianças com idade entre 4 e 5 anos). 
Quanto à "Ambientalização", no dia 01/04/2019 a equipe de estagiários realizou uma visita observacional em seu futuro cenário de trabalho. Desta vistoria buscou-se uma compreensão de como funciona o ambiente escolar, destacando o tamanho da sala de aula, a quantidade e como se agrupam os pré-escolares, seus horários de atividades, onde e de que forma se alimentam, além da avaliação da rotina e da viabilização da higienização bucal das crianças Imagem 02.

Imagem 2: “Ambientalização”, Autores (2019)

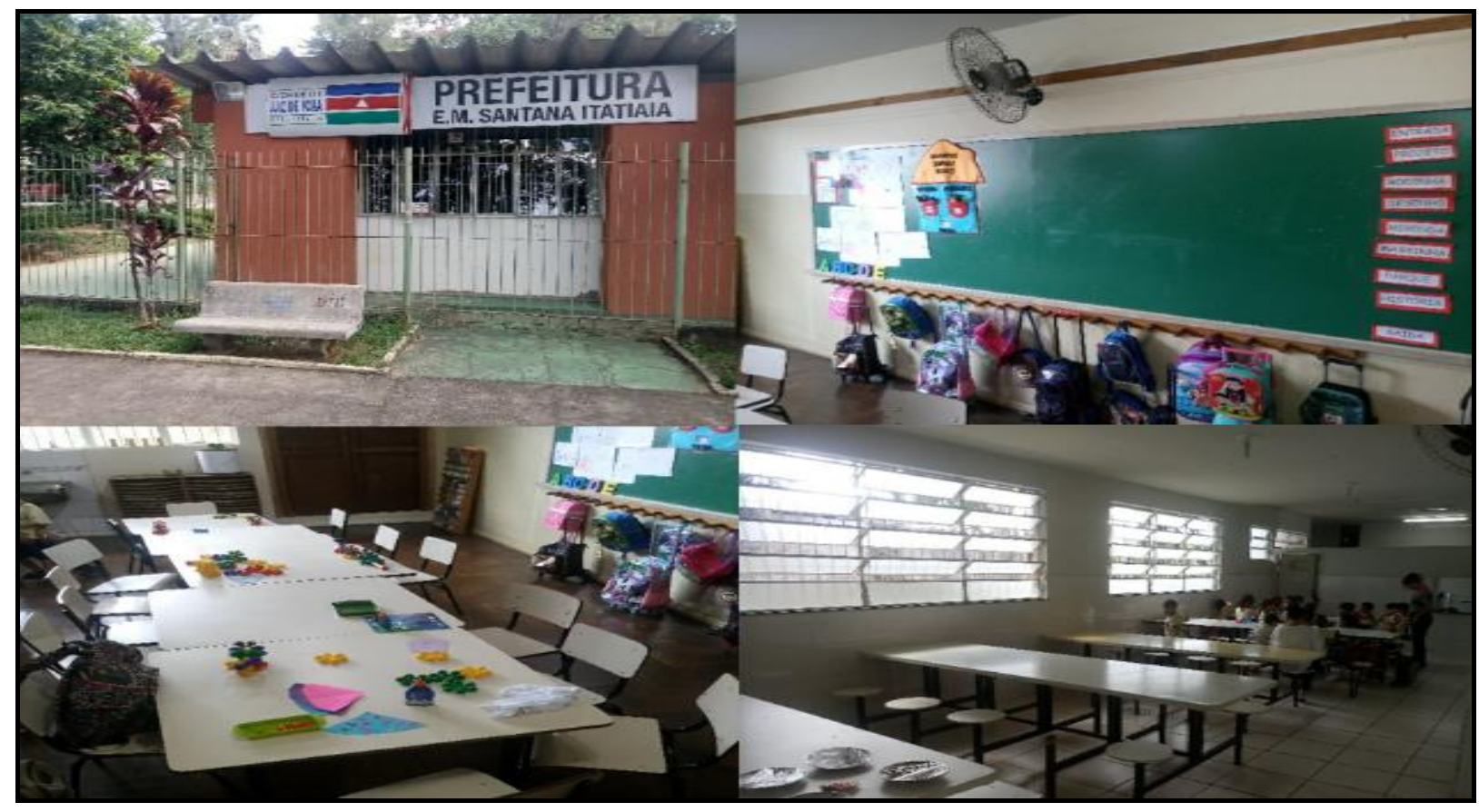

A visita do ambiente escolar se encerrou com o "Levantamento de necessidades do ambiente de trabalho". Daqui celebrou-se a pactualização das atividades a serem desenvolvidas na escola. Para tal, didaticamente, a equipe de estagiários se dividiu em duas pontas, uma destinada a entrevistar os professores para definirem a temática da ação ("O que vocês gostariam que falássemos?"), e outra a se aproximar das crianças para analisarem os tipos de atividades a serem desenvolvidas (“O que vocês gostam de fazer?”).

Após esta sistemática ficaram definidas a temática e a forma de trabalho, respectivamente, "Higiene bucal/autocuidado" e lucididade. Até aqui, refletindo um pouco sobre o vivenciado, torna-se fundamental destacar a importância deste momento de escuta, que vai de encontro aos preceitos educacionais de Freire (1983, 2006, 2007).

Segundo o educador, a academia deve romper com o ainda frequente movimento de "via de mão única", onde tudo é focado aos ensejos paternalistas da universidade, que vai à sociedade 
levar algo de sua especialidade, logo, se tornando antidialógica e manipuladora (FREIRE, 1983, 2006, 2007).

Neste processo, consumado pela quebra da verticalidade, vislumbra-se os moldes da "via de mão dupla". Assim, sustentada na integralidade da vida humana, a academia não apenas leva informações para a comunidade (ensino), como traz para o cenário universitário vivências (extensão) e dados coletados e interpretados cientificamente (pesquisa).

Contudo, apesar de sua importância, Almeida, Pereira e Oliveira (2016) reiteram que este fundamental período de escuta é normalmente burlado pelas ações da academia, consequentemente, p. 747, "gerando um modelo de trabalho vertical-paternalista, assistencialista e, principalmente, descontextualizado do controle social".

Encerrada a "Pré-intervenção", abriu-se a "Intervenção". A partir de então, na intenção de se prover um modelo de trabalho que extrapolasse o apenas "fazer", que também alcançasse "o pensar" e o "refletir", o "ECIAP" se via afinado às idealizações dos trabalhos de Almeida, Pereira e Oliveira (2016) e Almeida, Pereira e Bara (2009), que materializaram o instrumento "TPC" (Imagem 3). Segundo os autores, p. 746,

"O instrumento apresentado [...] se desenvolve em três etapas: Teorizando ("o pensar"), Praticando ("o fazer") e Criticando ("o refletir"), sendo por isso denominado TPC. Sistematicamente, as etapas se complementam, trazendo em seu bojo conceitual a relação entre planejamento estratégico com a eficácia, eficiência e efetividade de ações de educação em saúde" (ALMEIDA, PEREIRA, OLIVEIRA, 2016).

Imagem 3: Instrumento “TPC” (ALMEIDA, PEREIRA, OLIVEIRA, p.746, 2016)

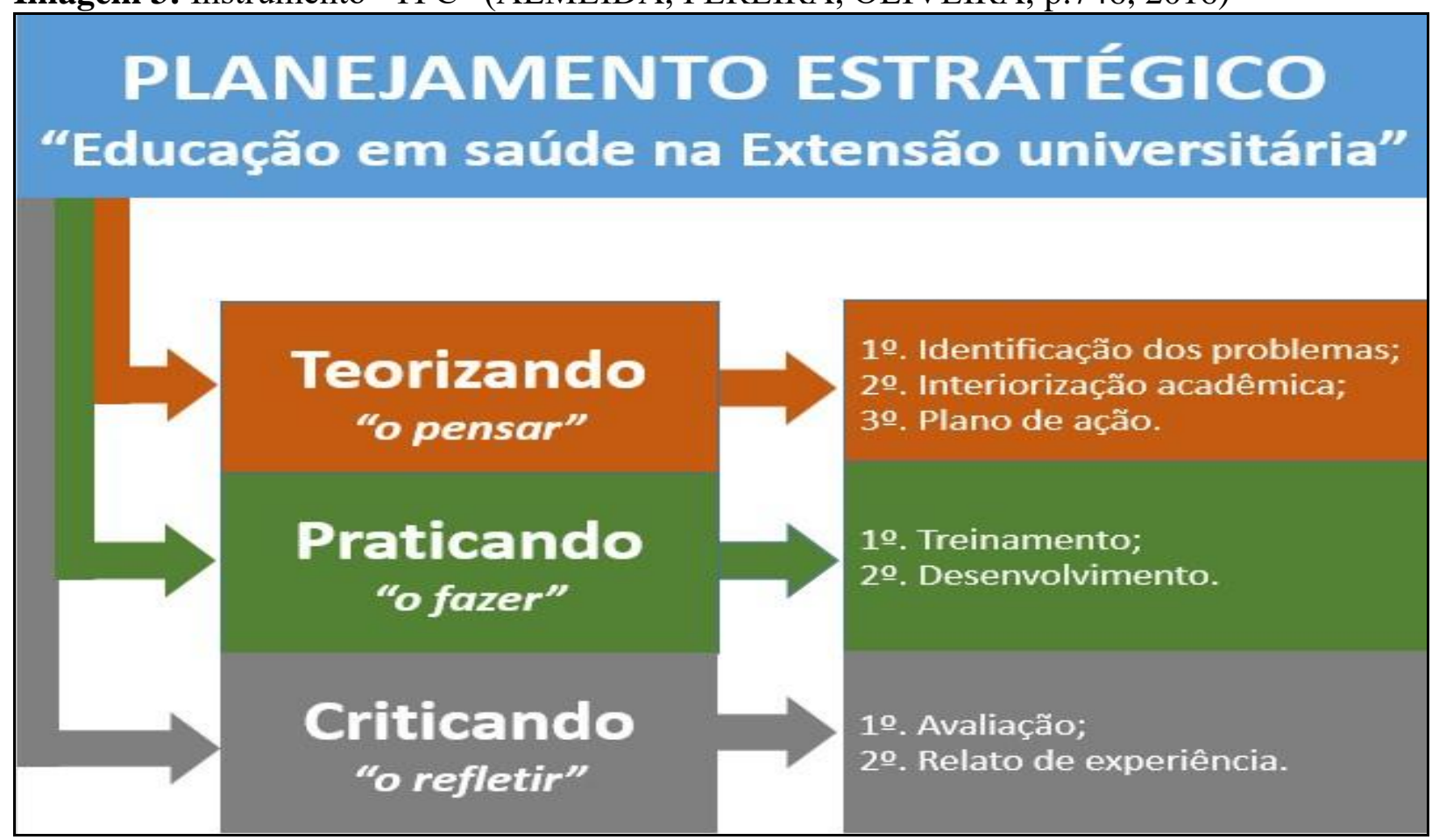


Aqui, tornam-se mister as considerações de Almeida, Pereira e Bara (2009). De acordo com os estudiosos, p. 129, o "TPC", não se consagra como uma "fórmula mágica", pelo contrário, a ferramenta apenas retrata a rica lógica do "ensinar a fazer contextualizado". Além, conforme os mesmos autores, o verdadeiro intuito do instrumento se efetiva na redução do persistente hiato entre teoria e prática, que, consecutivamente, se choca no necessário e desafiante alinhamento dos tempos de trabalho entre serviço e academia.

Desta forma, a dinamização da ação de educação em saúde no ambiente escolar foi perpassada pela sistematização do "TPC", ou seja, sequenciada em três etapas: "Teorizando/O pensar"; "Praticando/O fazer"; "Criticando/O refletir".

Assim, direcionados pelo instrumento, em 08/04/2019, deu-se o ponto de partida do planejamento estratégico das demandas de trabalho do Grupo II da Turma A, iniciando-se com a "Identificação do(s) problema(s)". Neste movimento, apesar da equipe estagiária saber "O quê fazer" (Desenvolver, aos preceitos da ludicidade, uma ação de educação em saúde junto a préescolares abordando a temática 'Higiene/autocuidado bucal'), a mesma se via diante de uma problemática central: “O como fazer?".

Assim, desafiados pelo questionamento, neste mesmo dia, partiu-se para a "Interiorização acadêmica". Daqui, foi solicitado aos estagiários o confronto dos ideários teóricos abordados durante a "Contextualização dos acadêmicos estagiários", com os desafios práticos levantados durante o "Levantamento de necessidades do ambiente de trabalho". Em outras palavras, os estagiários perceberam o seu real papel como acadêmicos, o de transformar conhecimento científico em instrumento para se mudar uma realidade.

O encontro foi encerrado com a criação de um "Plano de ação". Atravessado pelas preconizações da metodologia "Brainstorming”, a dinamização deste período retoma, através da utilização de um questionário direcionador (“O quê?”, "Quem?”, “Onde?”, "Quando?”, “Como?”, “Quanto custa?”, “Por quê?” e "Como avaliar?”) as orientações propostas pela metodologia do instrumento "TPC" (NÓBREGA, LOPES NETO, SANTOS, 1997; BRAIA, CURRAL, GOMES, 2014; ALMEIDA, PEREIRA, OLIVEIRA, 2016; ALMEIDA, PEREIRA, BARA, 2009).

Após amplo debate e alinhamento de ideias, foi delineado, através da concepção de um mapa conceitual (Quadro 01), o "Plano de ação" do Grupo II da Turma A do "ECIAP" (CABARETTA JÚNIOR, 2013; TAVARES, 2007). 
Quadro 1: Mapa conceitual do "Plano de ação" do Grupo II/A do "ECIAP” (Autores, 2019)

\begin{tabular}{|c|c|}
\hline \multicolumn{2}{|c|}{ "Plano de ação" - Educação em saúde em ambiente escolar - Grupo II/A } \\
\hline Questão direcionadora & Descrição \\
\hline "O quê??” & $\begin{array}{l}\text { Desenvolver, aos preceitos da ludicidade, uma ação de educação em } \\
\text { saúde junto a pré-escolares abordando a temática "Higiene/autocuidado } \\
\text { bucal". }\end{array}$ \\
\hline "Quem?" & $\begin{array}{l}\text { - Público-alvo: } 22 \text { crianças com idade entre } 4 \text { e } 5 \text { anos; } \\
\text { - Executores: } 04 \text { estagiários. }\end{array}$ \\
\hline "Onde?" & Sala 02 da Escola Municipal Santana Itatiaia, Juiz de Fora/MG \\
\hline "Quando?” & $\begin{array}{l}\text { - } \text { Dia: } 22 / 04 / 2019 \\
\text { - Horário de início: } 14: 00 \text { horas } \\
\text { - } \quad \text { Previsão de duração da ação: até } 30 \text { minutos. }\end{array}$ \\
\hline "Como?" & 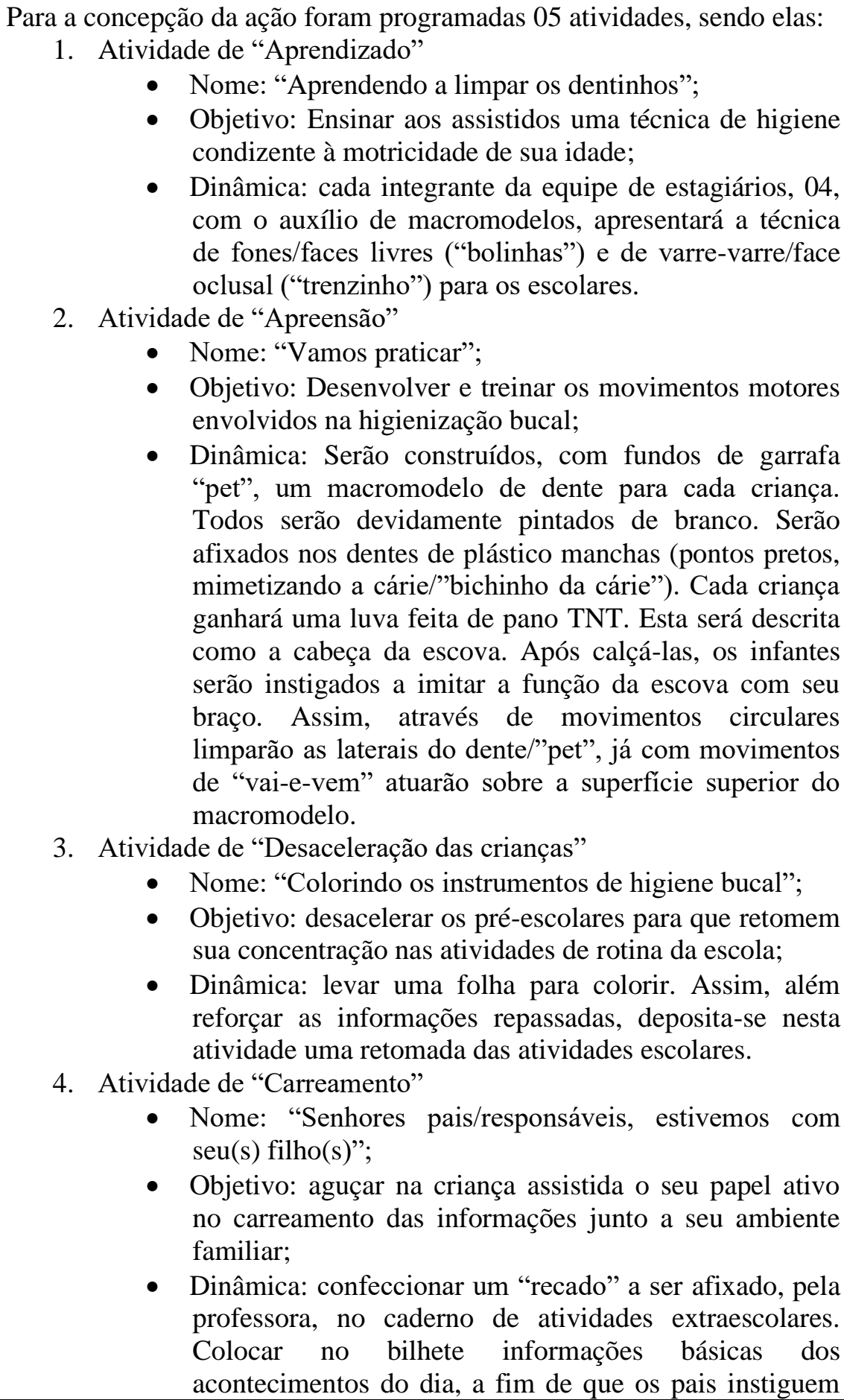 \\
\hline
\end{tabular}




\begin{tabular}{|c|c|c|}
\hline & $\begin{array}{l}\text { seus filhos a falarem sobre o qu } \\
\text { 5. Distribuição de "Kits de higiene bucal" } \\
\text { - } \\
\text { - } \text { bume: "Instrumentalizando pa } \\
\text { Objetivo: motivar hábitos sal } \\
\text { servirem como agentes politi } \\
\text { curso de Odontologia da UFJF } \\
\text { • Dinâmica: distribuir dois Kit } \\
\text { criança, garantindo desta forn } \\
\text { ambiente escolar, quanto no } \\
\text { intenção de estimular as ativi } \\
\text { escola, fornecer Kits para toda } \\
\text { que os Kits serão embalados e } \\
\text { fim de garantir a harmonia da s } \\
\text { • Nome: "O nosso escovário"; } \\
\text { - Objetivo: organizar os kits de } \\
\text { individual, para sua melhor con } \\
\text { Dinâmica: durante a entrega d } \\
\text { mostrar para a professora o es } \\
\text { como ele poderá auxiliá-la na } \\
\text { dos referidos instrumentos. }\end{array}$ & $\begin{array}{l}\text { vivenciaram. } \\
\text { uma adequada higiene } \\
\text { ares de autocuidado e } \\
\text { dores da presença do } \\
\text { n cenários extramuros; } \\
\text { de higiene bucal por } \\
\text { instrumentos tanto no } \\
\text { miliar. Além disso, na } \\
\text { des de autocuidado na } \\
\text { s professoras. Destacar } \\
\text { tregues à professora, a } \\
\text { a de aula. } \\
\text { igiene bucal de forma } \\
\text { rvação e acesso; } \\
\text { kits de higiene bucal, } \\
\text { vário. Detalhando a ela } \\
\text { rganização e no acesso }\end{array}$ \\
\hline \multirow[t]{6}{*}{ "Quanto custa?" } & \\
\hline & Descrição & Valor $(R \$)$ \\
\hline & Material de consumo para a dinâmica & 35,00 \\
\hline & Kits de higiene bucal* & 0,00 \\
\hline & TOTAL: & $35,00 * *$ \\
\hline & \multicolumn{2}{|c|}{$\begin{array}{l}\text { * os kits de higiene bucal foram fornecidos pela Faculdade de } \\
\text { Odontologia-UFJF; } \\
\text { ** os valores foram apresentados após a materialização de todos os } \\
\text { materiais didáticos previstos para a atividade. }\end{array}$} \\
\hline "Por quê?" & \multicolumn{2}{|c|}{$\begin{array}{l}\text { A justificativa se centrou na valorização da escola como terreno fértil } \\
\text { para o desenvolvimento de atividades de educação em saúde. Além } \\
\text { disso, a idade pré-escolar é um momento da criança fundamental para a } \\
\text { construção e consolidação de novos hábitos, incluindo aí a alimentação } \\
\text { saudável e a higiene bucal. }\end{array}$} \\
\hline "Como avaliar?" & \multicolumn{2}{|c|}{$\begin{array}{l}\text { Avaliação quanti-qualitativa: } \\
\text { - Quantitativa: avaliar a cobertura dos assistidos, através da } \\
\text { relação entre o número de crianças presentes e o número de } \\
\text { crianças esperadas [Cobertura }=(\mathrm{CP} / \mathrm{CE}) \mathrm{X} 100] \text {; } \\
\text { - Qualitativa: avaliar o grau de adesão dos envolvidos na } \\
\text { atividade. }\end{array}$} \\
\hline
\end{tabular}

Apesar de simples, extraiu-se da etapa de construção "Plano de ação" uma ferramenta indutora no engajamento dos discentes estagiários junto à solutividades de suas demandas. Uma reflexão que embasa o real papel da formação universitária, que não deve se restringir apenas ao fornecimento depositário de conhecimentos para o aluno (aprendizado), pelo contrário, deve aguçar no discente o desejo de aplicá-los (apreensão e carreamento), ou seja, ferramentas transformadoras de uma realidade social. 
Além, analisando a lógica educativa utilizada, pode-se afirmar que ela celebra a efetivação do enlace ensino-serviço-comunidade (UFJF-Escola Municipal Santana Itatiaia-Préescolares), vista a concepção das atividades planejadas partirem do contexto social ao qual estão inseridas, ou seja, mais importante que os próprios procedimentos didáticos, é ter consciência e conhecimento do "que" e, principalmente, de "quem" serão ensinados.

Encerrado seu estágio observacional (Teorizando/“O pensar”), os estagiários partiram para a etapa "Praticando/O fazer". O ciclo prático se iniciou com o "Treinamento". Neste dia, 15/04/2019, os acadêmicos (Grupo II da turma A) dinamizaram, junto aos professores/tutores, o "plano de ação" previamente idealizado (Quadro 01), agora, detalhadamente estruturado e materializado. No ensejo, este processo se destacou nos ajustes e alinhamentos finais nas ações a serem desenvolvidas no ambiente escolar.

Pode-se afirmar que esta etapa teve papel fundamental na preparação da equipe de estagiários. Afinal, ela marca, de forma gradual, a mudança nas funções dos discentes, que se deslocam da condição de observadores/idealizadores para interventores. Almeida e Oliveira Júnior (2009), p. 64, ainda complementam, “treinar não é eximir-se do erro, pelo contrário, no treino, através da mimetização de uma realidade, vislumbra-se capacitar uma equipe em prover estratégias secundárias para se contornar os tão frequentes e esperados obstáculos da vida real".

Assim, previamente treinados, chega o tão esperado "Desenvolvimento" do plano de ação, em 22/04/2019. Em linhas, em conformidade com o prévio plano de ação (Quadro 01), pode-se afirmar que as atividades de "Aprendizado" e "Apreensão" foram efetivas frente aos seus objetivos, que juntas, não apenas ensinaram como treinaram os assistidos junto a uma técnica de higiene bucal direcionada à motricidade de pré-escolares (Imagem 04).

Adensando um pouco mais, indo além do que se levou ao ambiente escolar de trabalho, a experiência representou um diferencial no processo formativo dos acadêmicos envolvidos. Pois além de representar a primeira experiência extramuros, ofertou, através do enlaçamento ensinosociedade, uma oportunidade dos acadêmicos compreenderem o processo saúde-doença de forma contextualizada e, principalmente, humanizada.

Tão logo, durante a despedida, foram deixados para os escolares Kits de higiene bucal, além de um escovário para acondicioná-los e otimizar seu acesso. Além disso, na intenção de acessar os familiares dos escolares, foi entregue à professora um bilhete para afixar no caderno de atividades extraescolares ("Carreamento").

Para encerrar este dia, os professores/tutores se reuniram com os estagiários para se iniciar a "Avaliação" da ação desenvolvida (Criticando/“O pensar”). Para tal, centraram-se nos critérios quanti-qualitativos definidos durante a construção do plano de ação, "Como avaliar". 
Daqui extraiu-se uma cobertura de 100,00\% (todos frequentes, 22 crianças), além do alto grau de adesão dos envolvidos durante o desenvolvimento de todas as atividades programadas.

Imagem 4: Desenvolvimento das atividades planejadas (Autores, 2019)

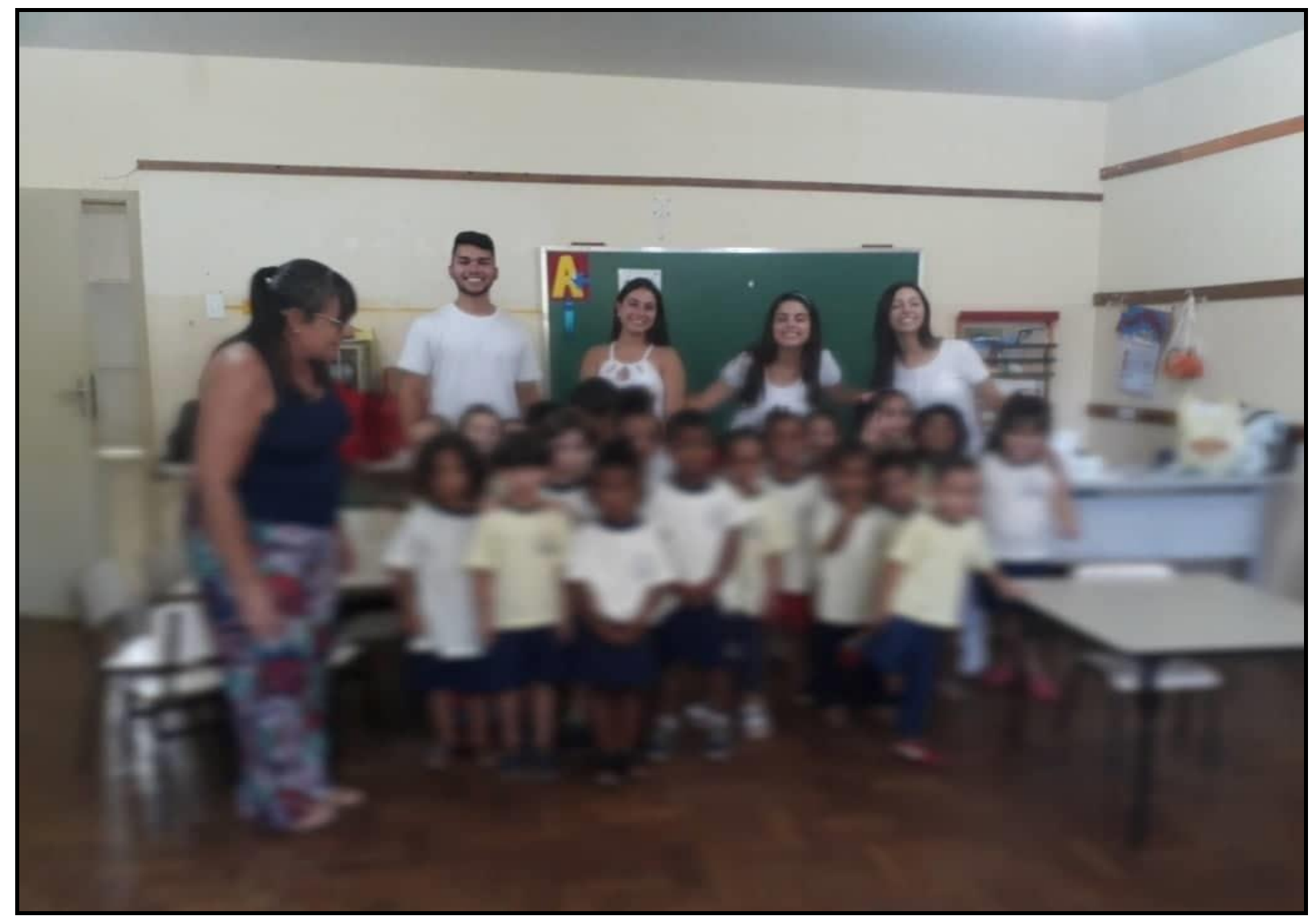

Adensando um pouco mais, refletindo sobre as experimentações vivenciadas pelo Grupo II/Turma A, apesar do êxito na execução do plano de ação, ficou evidente o sobrepujamento da realidade prática sobre as expectativas teóricas.

Foi justamente deste confronto entre "teoria/expectativa" e "prática/realidade" que se percebeu o "ECIAP" como agente ativo no processo de aprendizagem dos estagiários. Afinal, os acadêmicos puderam perceber que suas funções extrapolavam o "executar". Deles foram também exigidas outras habilidades, pautadas na plasticidade do "adaptar", do "criar", do "suprimir", do "postergar", e, principalmente, do "reinventar".

Assim os discentes tiveram a oportunidade de conhecer o maior desafio de um profissional da saúde, o saber lidar com os desafios e, até mesmo, entraves da realidade. Deixando de ver estas situações como alimento para frustrações, pelo contrário, passando a encará-las como uma oportunidade de melhoramento continuado. Percepções que se alicerçam 
no firmado por Almeida, Pereira e Oliveira (2016), p.747 "uma equipe aprende com os acertos e se transforma com os erros".

Indo além, engendra-se que a teoria não se torna diminuta diante da realidade, pelo contrário, ela ganha forma, sentido, em suma, se justifica. Neste prisma, como dito por Rossetti (1999), p.77, "Não se deve adaptar os pacientes à ciência, deve-se adaptar a ciência às pessoas". Complementando, o mesmo autor, p.27, “Aos doutores, ensiná-los a pensar, não aplicar técnicas ou receitas".

É óbvio que não se poderia esperar, pelo menos em totalidade, a compreensão dos graduandos estagiários das reflexões supradescritas. Por isso a terceira e última etapa do "TPC", "Criticando/O refletir", se fundamentou.

Como previsto, o percurso de reflexão se iniciou com a "Avaliação" e se encerrou com a construção do "Relato de Experiência", que integra o processo avaliativo do "ECIAP". De acordo com Almeida, Pereira e Oliveira (2016), p. 747, "entre as diversas metodologias, destacase o "relato de experiência", ressaltando que sua construção não deve ser direcionada apenas aos acertos, ou seja, deve-se oferecer espaço também para discutir erros e fragilidades".

Assim, reconhecendo o papel de divulgação e troca da publicação científica, com previsão de entrega para o dia 12/07/2019, o Grupo II da turma A do "ECIAP” buscou, através da materialização do presente artigo, compartilhar suas experimentações vivenciadas.

Por fim, sob análise global, pode-se afirmar que os cenários práticos ofertados pelos estágios são inesgotáveis para a aplicação dos conceitos disseminados em sala de aula e para o alicerce da pesquisa, em suma, fundamentais para o processo formativo dos futuros cirurgiõesdentistas.

\section{Considerações finais}

Após análise detalhada dos dispositivos político-pedagógicos atrelados à dinamização do "ECIAP", através das experimentações vivenciadas pelo Grupo III da Turma A, algumas inferências merecem destaque:

- a efetividade do instrumento "TPC" no direcionamento dos acadêmicos estagiários no planejamento estratégico de atividades de educação em saúde;

- o reconhecimento do ambiente escolar como território fértil para o desenvolvimento de ações promotoras de saúde;

- a importância de se disseminar, em espaços científicos, os aprendizados advindos de experimentações práticas de estágios. 


\section{Referências}

ALBUQUERQUE, V.S.; GOMES, A.P.; REZENDE, C.H.A.; SAMPAIO, M.X.; DIAS, O.V.; LUGARINHO, R.M. A integração ensino-serviço no contexto dos processos de mudança na formação superior dos profissionais da saúde. Rev. bras. educ. med, 32(3): 356-362, 2008.

ALMEIDA, L.E. PRÓ-SAÚDE: Ensino, Pesquisa e Extensão. Juiz de Fora: Editar Editora Associada Ltda, 2009.

ALMEIDA, L.E.; OLIVEIRA JÚNIOR, G.I. Sistema de Execução do Projeto. In: Almeida, Luiz Eduardo de (organizador). Pró-Saúde: Ensino, Pesquisa e Extensão. Juiz de Fora: Editar Editora Associada Ltda, 2009, pp.: 63-86.

ALMEIDA, L.E.; PEREIRA, M.N.; BARA, E.F. Projeto de Extensão Sabiá: a introdução de uma prática integralizadora no ensino odontológico. In: Almeida, Luiz Eduardo de (organizador). Pró-Saúde: Ensino, Pesquisa e Extensão. Juiz de Fora: Editar Editora Associada Ltda, 2009, pp.: 126-164.

ALMEIDA, L.E.; PEREIRA, M.N.; OLIVEIRA, V. Governador Valadares (MG) em Extensão: Interfaces para a Dinamização e Instrumentalização do Cenário Extensionista em um Campus Recém-Implantado. Rev. bras. educ. med., 40(4): 743-750, 2016.

BELL, J. Projeto de Pesquisa: Guia para pesquisadores iniciantes em educação, saúde e ciências sociais. Porto Alegre: Editora Artmed, 2008.

BRAIA, F.; CURRAL, L.; GOMES, C. Criatividade em contexto organizacional: o impacto de recompensas extrínsecas e do feedback negativo no desempenho criativo. Revista Psicologia, 28(2): 45-62, 2014.

BRASIL. Ministério da Saúde. Conselho Nacional de Saúde. Resolução n510, de 07 de abril de 2016. Brasília: Ministério da Saúde, 2016.

BRUDER, M.V.; LOLLI, L.F.; PALÁCIOS, A.R.; ROCHA, N.B.; VELTRINI, V.C.; GASPARETTO, A.; FUJIMAKI, M. Estágio supervisionado na Odontologia: vivência da promoção da saúde e integração multiprofissional. Rev Bras Promoç Saúde, 30(2): 294-300, 2017.

CARABETTA JÚNIOR, V. A Utilização de Mapas Conceituais como Recurso Didático para a Construção e Interrelação de Conceitos. Rev. bras. educ. med., 37(3): 441-447, 2013.

CRESWELL, J.W. Projeto de Pesquisa: Métodos qualitativo, quantitativo e misto. Porto Alegre: Editora Artmed, 2007.

FREIRE, P. Educação como Prática da Liberdade. Rio de Janeiro: Paz e Terra. 2007.

FREIRE, P. Extensão ou comunicação? Rio de Janeiro: Editora Paz e Terra, 1983. Disponível em

http://www.emater.tche.br/site/arquivos_pdf/teses/Livro_P_Freire_Extensao_ou_Comunicacao.p df. Acesso em 22 ago. 2019.

FREIRE, P. Pedagogia da Autonomia: saberes necessários à prática educativa. Rio de Janeiro: Paz e Terra, 2006.

LAGE, R.H.; ALMEIDA, S.K.T.T.; VASCONCELOS, G.A.N.; ASSAF, A.V.; ROBLES, F.R.P. Ensino e Aprendizagem em Odontologia: Análise de Sujeitos e Práticas. Rev. bras. educ. med., 41(1): 22-29, 2017.

LEME, P.A.T.; PEREIRA, A.C.; MENEGIM, M.C.; MIALHE, F.L. Perspectivas de graduandos em odontologia acerca das experiências na atenção básica para sua formação em saúde. Ciência \& Saúde Coletiva, 20(4):1255-1265, 2015. 
MADEIRA MC. Ensino, Pesquisa, Extensão. In: Carvalho, Antônio César Perri; Kriger, Léo (organizadores). Educação Odontológica. São Paulo: Editora Artes Médicas, 2006. pp.: 97-103.

MINAYO, M.C.S. Ciência, técnica e arte: o desafio da pesquisa social. In: Pesquisa Social: teoria, método e criatividade / Deslandes, Suely Ferreira (organizadora). Rio de Janeiro: Editora Vozes, 1994. pp.: 09-29. Disponível em <http://www.grupodec.net.br/wpcontent/uploads/2015/10/Pesquisa_Social.pdf >. Acesso em 22 ago. 2019.

MOIMAZ, S.A.S.; WAKAYAMA, B.; GARBIN, A.J.I.; GARBIN, C.A.S.; SALIBA, N.A. Análise situacional do estágio curricular supervisionado nos cursos de graduação em Odontologia no Brasil: uma questão de interpretação. Revista da ABENO, 16(4): 19-28, 2016.

NÓBREGA, M.M.; LOPES NETO, D.; SANTOS, S.R. Uso da técnica de brainstorming para tomada de decisões na equipe de enfermagem de saúde pública. R. Bras. Enferm., 50(2): 247256, 1997.

REUL, M.A.; LIMA, E.D.; IRINEU, K.N.; LUCAS, R.S.C.C.; COSTA, E.M.M.B.; MADRUGA, R.C.R. Metodologias ativas de ensino aprendizagem na graduação em Odontologia e a contribuição da monitoria - relato de experiência. Revista da ABENO, 16(2): 62-68, 2016.

ROCHA, J.S.; DIAS, G.F.; CAMPANHA, N.H.; BALDANI, M.H. O uso da aprendizagem baseada em problemas na Odontologia: uma revisão crítica da literatura. Revista da ABENO, 16(1): 25-38, 2016.

ROSSETTI, H. Saúde para a Odontologia. São Paulo: Editora Santos, 1999.

SALIBA, N.A.; MOIMAZ, A.S.; CHIARATTO, R.A.; TIANO, A.V.P. A utilização da metodologia PBL em Odontologia: descortinando novas possibilidades ao processo ensinoaprendizagem. Rev. odonto ciênc., 23(4): 392-396, 2008.

TAVARES, R. Construindo mapas conceituais. Ciências \& Cognição, 12(-): 72-85, 2007.

TINTI, E.C. Dilemas entre teoria e prática a partir da formação profissional e das condições objetivas do trabalho cotidiano. In: Capitalismo, trabalho e formação profissional: dilemas do trabalho cotidiano dos assistentes sociais em Ribeirão Preto. São Paulo: Editora UNESP, 2015, pp.: 97-131.

Recebido em 09/09/2019. Aprovado em 05/11/2019. 